\title{
The Automation Versus the Human Touch in the Boutique Hotels: Possible Limits
}

\author{
Miroslava Malcheva, PhD Student \\ University of Economics - Varna, Varna, Bulgaria \\ m.malcheva@ue-varna.bg
}

\begin{abstract}
As a leading economic sector in many countries around the world tourism industry is changing rapidly under the pressure of information and communication technologies spread in every activity into daily life and business. Almost unnoticed, technology and artificial intelligence have replaced humans in certain spheres. The question is whether their replacement is positive for the tourism supply or it is not even close. This is especially important for the boutique hotels offering innovative accommodation concept and personalized high-quality tourist product. The aim of the current study is to prove that boutique hotels need both - automated processes and human touch and to outline the limits of the right balance how to emphasize that symbiose in order to benefit of greater loyalty and ongoing revenues.
\end{abstract}

Keywords: boutique hotels, automation, personalized service, artificial intelligence, information and communication technologies

JEL Code: Z300; doi:10.36997/IJUSV-ESS/2019.8.2.155

\section{Introduction}

The development of electronic information and communication technologies is the basis for the expansion of e-business in the tourism sector (Marinov, 2015). The full extent of digitalization, robotics and virtual reality have been a central topic of modern business over the past few years. Although, according to most researchers and professionals in tourism, such futuristic plots are still inapplicable in certain geographic areas, more and more hotels are focusing their efforts on maximizing consumer satisfaction while respecting the principles of creating the so-called guest experience. Boutique hotels are no exception. Part of their modern concept is precisely the stable positioning in the Internet and the attainment of personal attitude to the user through the creation of personalized service. However, this same personalized service puts them at a crossroad. The limitations result from the fact that the high-quality standard is far from being limited to digital marketing and increased online presence in the web. Open face-to-face communication is essential when attending the specific market segment of high-class boutique hotels.

The purpose of this publication is to establish the limits of automation in the process of applying an individual approach in guest service. The goal is realized with the following research tasks: review of the specialized literature and clarification of the basic concepts and terms related to automation and digitalization; introducing a conceptual model for analysis and evaluation of the limits of automation in boutique hotels; defining the key features of digital marketing and Hospitality 4.0; systematizing examples and practices from the application of automation in the international hospitality business; providing guidelines and recommendations for the development of boutique hotels by successful combination of information technology with human factor in service.

\section{Literature review}

On the rise with information and communication technologies (ICT) introduction and application in all spheres of international business the English-language literature distinguishes three concepts: digitization, digitalization and automation (Schumacher et al., 2016). The first one refers to converting information into a digital format (Robinson, 2008; Parviainen et al., 2017). The second one describes the computer-based assistance and new media and communication technologies on social and professional level (Fitzgerald et al., 2013; Bukht et al., 2017). The term 
"automation" refers to the implementation of software products that empower the process of act without a human interference (Parasuraman et al., 2000; Frohm et al., 2008; Goldberg, 2012).

The application of automation is becoming applicable and accessible in all industries thanks to the Internet of Things concept (IoT). It combines products of consumption, durable goods, industrial components, public services and objects of daily use with Internet connectivity and analytics of data that transform the way people leave and interact with others (Rose et al., 2015). Researchers expect the following results: in 2025 there will be up to one hundred billion devices connected to the IoT; the majority of revenue will arise from the provision of value-added services; the positive impact of IoT on citizens, consumers, businesses and governments will include improvements in individual health and well-being, help governments to provide better infrastructure and reduce costs, support overall reduction of the carbon footprint, increase access to education and other public services, and will improve safety in transportation and energy efficiency (GSMA, 2014; Rose et al., 2015; Moura et al., 2018). It can be successfully applied in the spheres of smart banking, smart agriculture, smart building, childcare, domotics (automatization of home), sports performance, etc. (Novillo-Vicuña et al., 2018).

In 2017 Kotler et al. launched their first book on the so called "Marketing 4.0". In a general sense its purpose is associated with the transition from traditional to digital. In today's society being exclusive is considered old-fashioned. The success of the companies now lies in their attempts to exclusivity (Kotler et al., 2017). Technological revolution 4.0 gives impetus to the development of Hospitality 4.0 which is characterized by the following features:

$\checkmark$ Using technologies as a way to seek experiences;

$\checkmark$ Differentiation of marketing by age criteria - Baby Boomers are marketed with different contents and differentiated approach in comparison to Millennials and Generation Z;

$\checkmark$ Differentiated distribution of marketing budget - there is no need the marketing and advertising budget to be increased over the years, but to be allocated to the numerous micro-niches trough which the hotel can reach its potential guests via web usage;

$\checkmark$ Reputation management - hospitality business can also be seriously affected by new technologies. The online reputation now is highly dependent on content marketing, which is why some companies worldwide use online reputation management firms;

$\checkmark$ Automation as a leading factor for development - despite the ever-increasing importance of ICT, boutique hotels cannot afford the "convenience" of completely losing their human role in service supply, as the standard of said service falls significantly.

Hospitality 4.0 is a new business model strongly linked to automation and IoT. Although these technological innovations make operations much easier and way more efficient, the need for human intervention in controlling these processes will remain as important and necessary precondition. Technologies will not be independent of human supervision, as their functioning requires monitoring, special maintenance or even intervention in case of failure (Ivanov, 2019). For the managers remains the skillful combination of automation with the competent presence of the human workforce, e. g. achieving a happy medium in service and provision of good value for money. As Deon Roets, academic head at Capsicum, Advetech's culinary school states, consumers continue to become more educated and discerning, and any business in the hospitality industry is well aware of the need for their employees to be professional and effective in the workplace, and to ensure that valued visitors receive the best possible service and experience (Bizcommunity, 2017). The guest experience is regarded to the traveler's interaction with the hotel and includes the stages of pre-consumption, consumption and post-consumption (Kandampully et al., 2015).

The assessment of advantages and disadvantages of fully implementing automation in hotel services depends on the strategy of the companies. Boutique hotels should set boundaries in which the succession between innovation and consumers leads solely and only to a high value of service ratings. 


\section{Methodology}

The extent to which automation will be implemented as an integral part of the service depends on the hotel itself. With their unique presence in the hotel industry, boutique hotels differ not only in the high level of service quality but also in the personalization of this service, provided in an innovative, differentiated and strictly individual atmosphere. Rather than offer standardized service and practices with rote protocols and rigid systems, boutique hotels can really focus on providing an outstanding, memorable experience (Malcheva, 2018).

Automation can successfully mediate the coordination between the goals initially set in the hotels strategy and its value chain, which is necessarily linked to building a lasting connection with potential and actual guests (fig. 1).

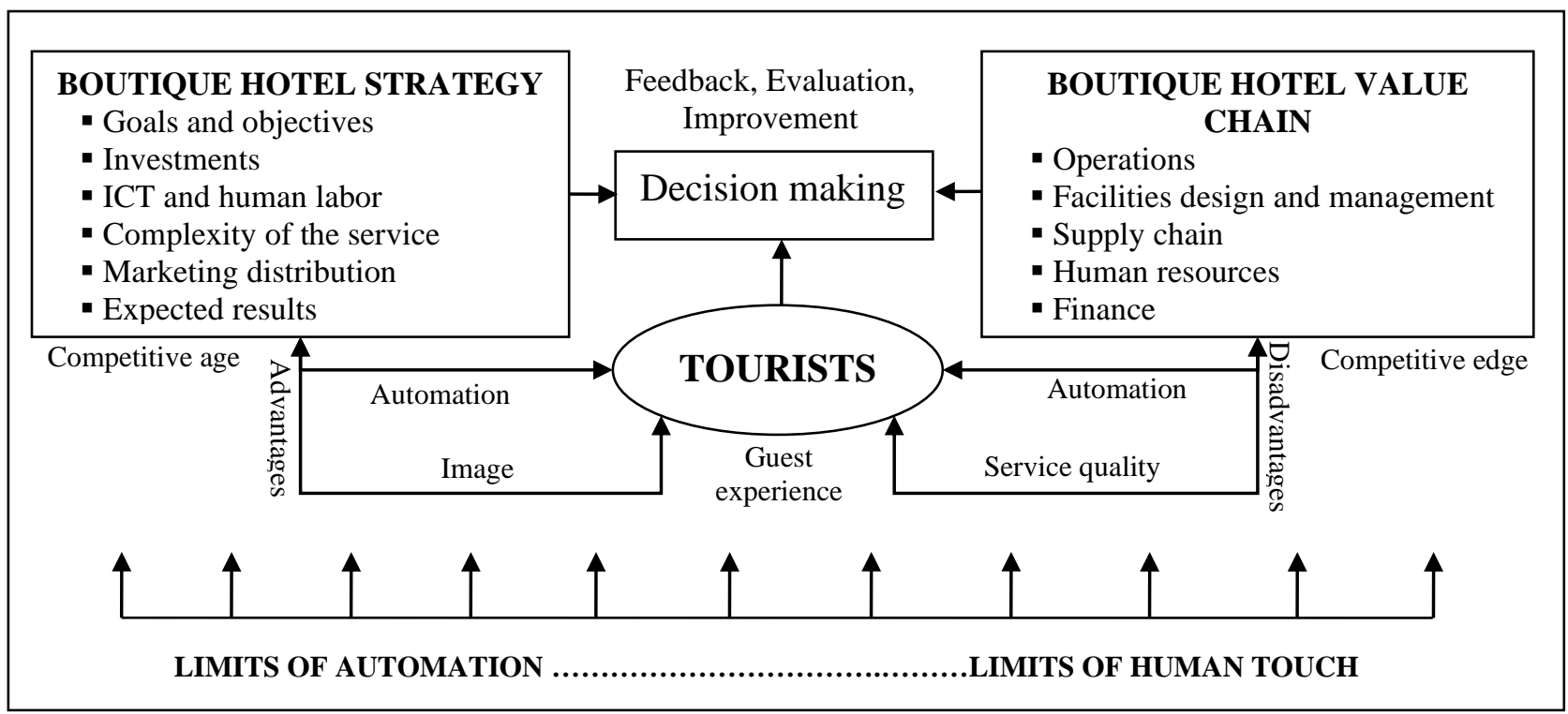

Fig.1. Possible limits of implementing automation in boutique hotels services.

At the heart of this relationship is the experience of the guest which could be described in the context of boutique hotels as following (Sabre Altimeter, 2018):

- A "five-star" experience based on the hotel's intuition and engagement;

- A delightful experience which starts with the customer's empathy and with a sense of globality;

- An innovative experience where technological transformation and the automation are building a construct that optimizes guests' feelings and memories;

- A personal experience built on relationship, loyalty, mutual respect and appreciation.

The strategy of the boutique hotel is created in a competitive age where automation is an integral part of the supply process. The role of the automation could be considered in two ways. On the one hand, it could improve the market image of the hotel and to achieve a high service quality. On the other hand, it could seriously harm the working process in those cases when hotels management relies solely on online interaction with customers and focuses on the use of robotic service systems. Finding the balance between machine intervention and human factor intervention is positioned at the base of the relationship "competitive age - competitive edge". All this leads to the full meeting of modern traveler's needs: personalization, differentiation, convenience, immediacy (Sabre Altimeter, 2018). The importance level of providing personalized services will remain the same for the boutique hotels. This is why "personalization" has become a buzzword in contemporary high-class hospitality industry. Even through social media or other digital networks, every purchase should be "touched", as customers do value the personal touch in their demand process. 


\section{Application of automation in boutique hotels services}

If one introduces the word "automation" into Google search engine, they will find more than 570 million results, according to which the term could be attributed as part of several main groups:

* Technological processes;

* Computer/intelligent systems;

* Virtual reality;

* Automation paradox.

The last concept was introduced back in 1983 by Lisanne Bainbridge, a researcher at the University of Reading in the United Kingdom (UK), in her paper "Ironies of Automation" (Bainbridge, 1983). The paradox is regarded to automation as taking the easy part of the task and leaving the hard one to people. It is debatable whether this could be considered an absolute truth then and now. With the dynamic advancement of technology, automated processes are becoming more autonomous and there is no need of constant human control. However, human intervention is necessary especially when providing highly individualized services, whose users need special attention.

Another feature found on Google Search is the constant juxtaposition between automation and human labor force: Will machines replace humans in....? This question could be applied to the hotel business too. The author's position is that automation has its place and reasons for application in hospitality as long as it does not completely shift the hotels priorities regarding the price-quality ratio.

The application of innovative technologies in the operation of boutique hotels can be considered in three aspects:

○ Design and atmosphere - audio and video intercoms, intelligent motion detectors, energy efficient intelligent lighting management system, optimal control of heating, air conditioning and ventilation, reliable security and alert system, evacuation lightning system, USB chargers, precise and smooth elevator control, one-touch light scenes and blind control, presence detectors, motion-enabled and keycards-enabled guest rooms, etc;

○ Ways of working and servicing - room service robots, mobile check-in services and robot-staffed front desk, artificial intelligence translators on the reception (multilingual robots), robotic concierges, housekeeping delivers and bellboys, etc;

○ Intangible services and Internet presence - guest messaging, real-time online presence, chat-bots, prompt computer processing of requests and reservations, applications indicating important information about the hotel services and events in the host city and others.

The opinions of the specialized sites are united around the thesis that some roles were created to be performed by robots. Rather, these are standardized activities such as checking-in and receiving general information about the services offered at the hotel. In practice, this does not minimize the power of the human factor. Each inclusion of a person in the service brings additional value for the guest. This is the reason why professionals consider the hotel industry as a partially automated sector where the human touch would never be completely lost.

Luxury hospitality brands are now facing the challenge to focus on experience-based guest services. By 2025, boutique hotels should have developed their strategies according to some obligatory conditions and requirements without which their existence in the digital age would not have been possible. The first one is the investment in the "art-of-the-experience" (Cognizant, 2017). Getting to know the depths of consumer needs is way more different from classical loyalty programs. Systemizing and including data from online and offline interactions should be considered as a long-term task with strategic role for further service providing. The second one is the general management will to invest in innovations, such as beacons, robotic systems and security alerts of new generation. The third one is the examination of the data. With new technologies spread in every 
daily activity boutique hotel staff should be aware of the information provided by the guests in social media networking and specialized sites. Content marketing should not be ignored neither. The hotel provider has to apply a differentiated approach when distributing its services on a global scale, using tools such as own website, third-parties' websites, call centers, blogs, specialized travel online magazines or even people (influencers, bloggers, digital nomads, etc.). Last but not least, the hotel should establish its own internal rules and concepts for the use of IoT. IoT readiness should be determined and the safety and security of the sensitive data should be not exposed to hacking.

\section{Limitations on the use of automation in boutique hotels}

While artificial intelligence and automation keep infiltrating the business worldwide, boutique hotels are challenged to hold their positions as providers of extremely personalized service with an individual message. The application of ICT systems and IoT has its benefits (Benbria, 2016):

$\checkmark$ The general advantage for the hotel is the time saving. By using mobile guest messaging and robotic systems to respond to a variety of questions and requests, the boutique hotel actually provides sufficient time for its staff to devote to complex cases that the robots themselves are not capable of solving. Also, automation guarantees prompt response to the guest. Tourism is a social industry in which the direct contact with the consumer is inevitable. Meanwhile, indirect communication mediated through virtual intermediaries should not be forgotten and delayed. Automation eliminates the obligation for the staff to respond promptly to any message, reservation or request. Hotel automation can help to reduce the costs and increase the efficiency and efficacy of certain services.

The need for maximum guest comfort and the green orientation of many boutique hotels can be assured by the development and implementation of building automation software. The built-in IT solution accumulates and analyzes information from many systems in the hotel. The reservations and accommodation of the guests are monitored, optimizing the energy consumption by activating only the occupied rooms. The air-conditioning and domestic hot water systems are combined, which allows for a reduction of energy losses many times. There are developed systems for monitoring the external illumination and the presence of people in the premises, which automatically controls the illumination of the common rooms and electric consumers in the rooms. Artificial intelligence replaces the need for more staff members, minimizes the energy costs and this way increases the revenue. Automation can be also successfully implemented in the housekeeping department to achieve a high standard of maintenance from an operational point of view, as well as to facilitate the physical labor of staff, allowing them to focus on value-added services and attendance.

$\checkmark$ The benefits for the guest lie in the ability to manage the accommodation and service processes on his own. Freedom is one of the basic requirements of the modern consumer. Automation does not, in fact, oblige the guests to use robotic standard services, but gives them a choice to take advantage of technological innovations. Automation also provides opportunities for the hotel to develop its own "personal management system" (PMS). By organizing guest information from online and offline space, the boutique hotel has the opportunity to create a personal portfolio of its guests that could be used for further services. This way the guest receives the most personalized accommodation possible and feels valuable, important and unique.

Researches state that by $2020,85 \%$ of the customers will interact with the companies without human intervention. By now, $65 \%$ of consumers connect to the service providers through chat-bots or another virtual intermediary (Bassano, 2018). Increasingly luxurious hotels offer a hotel guest journey supported by $21^{\text {st }}$ century technology and artificial intelligence - a Virtual Host. The guests receive on their mobile devices the following message: "If I may be of assistance, please 
text me". The Virtual Host is a new online guest engagement service which guide you through your stay from the moment you book your room - the guest could check-in online before the arrival and even could choose the floor and the room. Before guests arrive in the hotel, they could ask the virtual assistant if the room is ready and also could receive the GPS coordinates of the hotel. Through the virtual host every guest could order a room service or to book a spa procedure. The hotel restaurant staff receive those orders directly on a mobile device or tablet. The hotel staff could receive the guests request no matter where they are at that moment. The virtual host is always focused on personalizing the stay. The guests can add to their virtual profiles all food preferences and even what they are allergic to. This information is available to the restaurant staff and helps them to offer to the clients the best meal options (AppAdvice, 2019).

However, this does not mean that artificial intelligence will eliminate the need for human intervention in all sectors of the economy. As Bassano states, customer satisfaction largely comes from establishing good relationships-these relationships are essential to the success of every business. But without human interaction, there can be no relationship in the first place. As engaging as robots can be, customers still bond with people (Bassano, 2018). The $100 \%$ application of automation in high-class hospitality business can cause a number of problems not only for the hoteliers but also for their real and potential guests. Machines are far from easy to operate and users' needs will become more and more unlimited.

The problems that automation can cause to the boutique hotel and its guests can be systemized in the following directions:

- Issues are always possible if the machines are allowed to run rampant (Jukes, 2019). This again puts to the forefront the essential role of people who are constantly monitoring, updating, moderating and checking the performance of computer systems;

- Big data, including personal information could easily appear in the "hands" of third parties whose purposes may be malicious. The IoT requires careful distribution of information, and only to innocent accounts which owners will use the hotels messages in connection with the purchase of its services and products;

- The displacement of human factor in services can seriously harm employment levels in tourism and other sectors of services as a whole. Increasing unemployment rates can be devastating, especially for countries where tourism sector is a leading industry;

- Automation can be a factor in the negative image of a boutique hotel if it cannot adapt its services to all age groups. Some of the older guests may have issues using the new technologies that make it difficult for them to plan and realize their stay. Understood as extras the automatic check-in, remote control of the lights and modern room unlocking can turn into a disadvantage for the hotel if its guests cannot use the innovations optimally and fully.

- Artificial intelligence and the introduction of automated service processes require serious investment by the hotelier. Therefore, it is important for the boutique hotel to accurately determine the boundaries of application, because such investments are more likely to return slowly;

- Remains the risk that the guest may feel undervalued. It is no accident that information technologies are considered as cold tourism intermediaries. Although modern, they offer standardized operations and answers to questions and requests. Not every user agrees to communicate with chat-bots or robots. Often the answers they offer to the guest are rather evasive, lacking in diversity and personal attitude that can only be ensured through contact with a human being;

- If it does not research and consult its real and potential guests in advance, the boutique hotels management risks making a huge mistake in assessing when, to what extent, and to which market segments to offer automated innovative products. Thus, the advantage becomes a disadvantage, which can weaken the market position of the hotel and reduce the level of trust in 
loyal customers;

- Some physical innovations have their own individual appearance, which cannot be completely changed according to the interior design of the hotel. Thus, the preliminary design concept may be disturbed, and inappropriate and illogical interior solutions may be obtained.

\section{Conclusion}

Automation is an inevitable process that will sooner or later become part of people's lives in their daily activities, at their jobs, and also during travel. Boutique hotels, as ambassadors of the non-standard and at the same time seeking maximum comfort for guests, must carefully select technological solutions in the service processes to earn more positives. This eclectic style of blending traditional hospitality with extraordinary guest care and the introduction of automated guest service processes must be balanced. By regularly checking the guest's opinion on any technological innovation, the boutique hotels should take into consideration any feedback from customers. The smooth introduction of new technologies in boutique hotels is crucial in order not to lose sentiment on personal contact. For this type of industry, the point is that business is based on interconnections, which, if not entirely, involve at least some element of face-to-face interaction. Considering the pros and cons of automation in the present paper, we can conclude that, in boutique hotels, the degree of application of these innovative processes should be limited to the willingness of actual and potential guests to take full or partial advantage of the proposed ICT solutions. In this way, the boutique hotels can refine their investment for innovations, minimizing unnecessary costs while achieving the desired benefits.

\section{References}

1. AppAdvice. (2019) Edward, the virtual host. [Online] Available from: http://bit.ly/32CaE4n [Accessed 03/11/2019].

2. Bainbridge, L. (1983) Ironies of Automation, Automatica, 19(6). pp. 775-779.

3. Bassano, C. (2018) How to Find the Balance Between Automation and Human Support. [Online] Available from: http://bit.ly/2O3wUPg [Accessed 11/11/2019].

4. Benbria. (2016) How Hotel Automation Benefits Guests. [Online] Available from: http://bit.ly/33EIbMx [Accessed 11/11/2019].

5. Bizcommunity. (2017) Tech can't replace the human touch in customer experience. [Online] Available from: http://bit.ly/2KbWxfB [Accessed 11/11/2019].

6. Bukht, R. \& Heeks, R. (2017) Defining, Conceptualising and Measuring the Digital Economy, Manchester Centre for Development Informatics Working Paper 68. pp. 1-24.

7. Cognizand. (2017) Hospitality in the Digital Era: The Road to 2025. [Online] Available from: https://cogniz.at/34P2dUJ [Accessed 11/11/2019].

8. Fitzgerald, M., Kruschwitz, N., Bonnet, D. and Welch, M. (2013) Embracing digital technology, MIT Sloan Management Review. [Online] Available from: https://bit.ly/2JP3aH0 [Accessed 11/11/2019].

9. Frohm, J., Lindström, V., Winroth, M. and Stahre, J. (2008) Levels of Automation in Manufacturing, International Journal of Human Factors and Ergonomics. 30 (3). pp. 1-28.

10. Goldberg, K. (2012) What is Automation? IEEE transactions on automation science and engineering. 9 (1). pp. 1-2.

11. GSMA. (2014) Understanding the Internet of Things (IoT). London: GSM Association.

12. Ivanov, S. (2019) Ultimate transformation: How will automation technologies disrupt the travel, tourism and hospitality industries? Zeitschrift für Tourismuswissenschaft 11 (1). (forthcoming).

13. Jukes, L. (2019) Digital automation vs human touch. [Online] Available from: http://bit.ly/32EgiCS [Accessed 11/11/2019]. 
14. Kandampully, J. and Solnet, D. (2015) Service Management: Principles for Hospitality and Tourism. Kendall Hunt Publishing, Iowa.

15. Kotler, Ph., Kartajaya, H. and Setiawan, I. (2017) Marketing 4.0. Moving from Traditional to Digital. New Jersey: John Wiley \& Sons, Inc.

16. Malcheva, M. (2018) Competitive Advantages of Boutique Hotels in the Context of a Sharing Economy. Izvestia Journal of the Union of Scientists - Varna, Economic Science Series. 7 (3). pp. 71-83.

17. Marinov, S. (2015) Vazmojnosti na informacionnite tehnologii za razvitie na sistemata za upravlenie na turisticheska destinacia. Sb. statii "Tendencii i predizvikatelstva pred globalnia turizam”. Infrastructure and communications. Sofia: UNWE, pp. 292-298.

18. Moura, P. and Nicoletti, S. (2018) Ciudades inteligentes e Internet de las cosas: cómo fomentar su desarrollo en América Latina. Santiago: GSM Association of Latin America Offices.

19. Novillo-Vicuña, J., Rojas, D., Olivo, B., Ríos, J. and Villavicencio, O. (2018) Arduino y el internet de las cosas. Alicante: Editorial Área de Innovación y Desarrollo, S.L.

20. Parasuraman, R., Sheridan, T. \& Wickens, C. (2000) A Model for Types and Levels of Human Interaction with Automation, IEEE transactions on systems, man, and cybernetics - part A: Systems and Humans 30 (3). pp. 286-297.

21. Parviainen, P., Tihinen, M., Kääriäinen, J. and Teppola, S. (2017) Tackling the digitalization challenge: how to benefit from digitalization in practice. International Journal of Information Systems and Project Management. 5 (1). pp. 63-77.

22. Robinson, D. (2008) Analog. In Fuller, M. (eds.), Software Studies: A Lexicon, edited by Mathew Fuller. Cambridge: MIT Press. pp. 21-31.

23. Rose, K., Eldridge, S. \& Chapin, L. (2015) La internet de las cosas - una breve reseña. Reston: Internet Society.

24. Schumacher, A., Sihn, W. and Erol, S. (2016) Automation, digitization and digitalization and their implications for manufacturing processes, Innovation and Sustainability, International Scientific Conference Bucharest, Romania, pp. 28-29.

25. Sabre Altimeter. (2018) Digital transformation of the guest experience. [Online] Available from: http://bit.ly/2Q8BzSB [Accessed 11/11/2019]. 